\title{
Actions monitoring as an alternative to structural rehabilitation: Case study of a river bridge
}

\author{
Francesco Ballio (1D | Giulio Ballio | Silvio Franzetti | Gianluca Crotti | Giovanni Solari
}

Department of Civil and Environmental Engineering, Politecnico di Milano, Milan, Italy

\section{Correspondence}

Francesco Ballio, Politecnico di Milano, Department of Civil and Environmental Engineering, Piazza Leonardo da Vinci 32, Milan 20133, Italy.

Email: francesco.ballio@polimi.it

\begin{abstract}
Summary
A number of river bridges collapse worldwide every year during flood events, due to combination of actions including traffic loads, water and wind load, riverbed degradation, and accumulation of debris. Incidence of failure is higher for relatively old bridges that may have been designed without adequate consideration for some of such actions, in particular the scour potential at piers and abutments; in this case, consolidation of bridge foundations may be required. As an alternative to structural rehabilitation, we propose here realtime management as a nonstructural risk-mitigation measure: Data from a monitoring system aid the bridge managers to decide whether a bridge should be partially or totally closed to traffic in the case that forecasted environmental conditions indicate that the structure may exit its safe operational domain. A peculiar feature of the present proposal is that the monitoring system focuses on the evaluation of the environmental actions on the structure rather than on the health state of the structure itself: Such choice allows sufficient lead time for bridge closure. Bridge management may not prevent the damage of the structure but should avoid casualties. The methodology is presented with reference to the field case of a bridge over the river Po (Italy); its generalization to a larger variety of conditions is also discussed.
\end{abstract}

\section{KEYWORDS}

bridge monitoring, bridge safety, nonstructural risk mitigation, real-time management, river bridge, scour

\section{1 | INTRODUCTION}

Statistics of bridge collapse in several countries around the world indicate hydraulic processes as the main triggering cause. Wardhana and Hadipriono ${ }^{1}$ state that "Over 500 failures of bridge structures in the United States between 1989 and 2000 the most frequent causes (...) were attributed to floods and collisions. Flood and scour (...) contributed for almost 53\% of all failures. Bridge overload and lateral impact forces from trucks, barges/ships, and trains constitute $20 \%$ of the total bridge failures. Other frequent principal causes are design, detailing, construction, material, and maintenance." This study confirms results of the previous analysis in Rhodes and Trent, ${ }^{2}$ who indicated "average annual flood-damage repair costs of approximately $\$ 50$ million for highways on the Federal-aid system." In addition to scour, authors underline the role of morphological evolution of the rivers, so that bridges "experience problems with aggradation, degradation, bank erosion, and lateral channel shift during their useful life." The relevance of scour on bridge failure in the United States has been recently analyzed in detail by Briaud et al. ${ }^{3}$ 
A worldwide dataset ${ }^{4}$ shows that natural hazards are the main causes of bridge collapse, with flooding or scour being responsible for around $60 \%$ of the events. Scour has also been indicated as the first responsible for bridge collapse in New Zealand. ${ }^{5,6}$ Similar results for the Italian road and railway systems are reported in Ballio et al. ${ }^{7}$ Azhari and Loh $^{8}$ and Bao and $\mathrm{Liu}^{9}$ show cases from other countries in the world, confirming that bed level variations and local scour around bridge foundations are predominant factors in bridge failures.

Historical evidence of vulnerability of river bridges has raised attention of the technical community on hydraulic processes: A comparative analysis of some national building and maintenance codes over the last 20 years reveals that, with respect to the past, recent codes provide more explicit and punctual indications to designers and managers on how to evaluate and take into consideration the interactions between the river system and the structure. ${ }^{10}$ As stated in Arneson et al, ${ }^{11}$ "The added cost of making a bridge less vulnerable to scour is small when compared to the total cost of a failure which can easily be two to ten times the cost of the bridge itself. Moreover, the need to ensure public safety and minimize the adverse effects resulting from bridge closures requires our best efforts to improve the state-of-practice for designing and maintaining bridge foundations to resist the effects of scour."

Evolution of codes is expected to grant higher level of safety for bridges (some evidence comes from a time series analysis in Briaud et $\mathrm{al}^{3}$ ). However, it also makes several existing structures to be no more compliant with the new standards, considering the increase of the nominal traffic and wind loads in the last 60 years and the modification of reference hydraulic hazard scenarios due to climate change. ${ }^{12}$ Therefore, "because it is not economically feasible to construct all bridges to resist all conceivable floods, or to install scour countermeasures at all existing bridges to ensure absolute invulnerability from scour damage, some risks of failure from future floods may have to be accepted." ${ }^{11}$

In this paper, we propose to consider real-time management of river bridges as a nonstructural risk-mitigation measure as an alternative (or in addition) to the standard structural countermeasures. More specifically, we propose a decision support system, based on a monitoring infrastructure, which aids the bridge managers to decide whether a bridge should be partially or totally closed to traffic due to a forecast of particularly harsh environmental conditions that may lead the structure to exit its safe operational zone. Bridge management may not prevent the damage of the structure but should avoid casualties. Such a strategy is consistent with the indications of the Eurocode EN $1990,{ }^{13}$ which states (clause 2.2) that "the measures to prevent potential causes of failure and/or reduce their consequences may, in appropriate circumstances, be interchanged to a limited extent provided that the required reliability levels are maintained." In fact, the possibility of limiting risk by some active management of the system connected to expected scenarios of environmental conditions rather than by intrinsic, passive resistance to actions is an accepted practice for a variety of systems. Significant examples are preventive evacuations for hurricanes, mobile levees systems for river floods, the "MOSE" system against high tides in Venice, speed reduction for high-speed trains rather than stopping windmills, or harbor cranes under extreme wind conditions. The specific case study under discussion in this paper is a road bridge over the Po River, Italy. The structure, built in the 1960s, is relatively well preserved; however, traffic and wind nominal loads are larger with respect to the design values, and there is historical evidence of a strong variation of the riverbed elevation at the bridge cross section, which was not originally accounted for. Analysis of past events and the simulation of possible future scenarios show that a proper management protocol of closure of traffic on the bridge, based on indications from a monitoring system, allows for adequate safety with respect to casualties without significant impact of the functionality of the infrastructure. Real-time monitoring system for the evaluation of vulnerability of river bridges has been already proposed in the literature. ${ }^{14,15}$ A peculiar feature of present proposal is that the monitoring system is focused on the evaluation of the environmental actions on the structure rather than on the health state of the structure itself. As described in the body of the paper, such choice is in this case necessary, as warning based on variation of properties of the structure would not give sufficient lead time for the actions necessary for bridge closure. With respect to a structural pier reinforcement, the nonstructural strategy here adopted is advantageous in that (a) it is less expensive; (b) through a continuous monitoring, it provides a deeper knowledge of the environmental actions on the structure; and (c) it is more flexible and adaptable to future changes of the environmental scenarios. The necessity of a technological system and a management plan for guaranteeing the required safety constitutes the obvious drawback of the proposed solution.

The paper is organized as follows. Section 2 provides a description of the case study, including the geometrical and structural properties of the bridge, the quantification of the loads acting on the structure, and the analysis of the possible collapse mechanisms. In Section 3, the structure is analyzed through a standard perspective of safety assessment; conclusion on the exercise is that the bridge cannot be considered as sufficiently safe with respect to possible (although improbable) load scenarios. Section 4 presents the innovative core of the paper, describing the component of the management scheme that allows for preserving people's lives also under extreme load scenarios. In the final discussion 
section, possibility of generalizing the specific case here presented to a wider range of environmental and structural conditions and/or of structures at risk is discussed within a conceptual scheme of "damage prognosis" (see, e.g., the model proposed in Farrar and Worden ${ }^{16}$ ) linking the monitoring approach here proposed to the more classic approach of structural health monitoring. ${ }^{17-19}$

\section{I CASE STUDY}

The structure under consideration is a state road-bridge crossing river Po close to the village of Borgoforte. The total length of the bridge is $630 \mathrm{~m}$, whereas for normal flow conditions, the river is about $300 \mathrm{~m}$ wide, so that only four of the 44 piers have permanently submerged foundations (Figure 1a), the remaining ones being positioned on the flood plain. Piers in the main channel of the river have two rows of three circular piles (Figure 1b).

After a flood in year 2000, a bathymetric survey indicated the presence of a residual scour hole between the two central piers in the river (Piers 31 and 32), whose maximum depth was $15 \mathrm{~m}$; it is reasonable to assume that larger depths may have been reached during the flood event. Therefore, piers from 31 to 33 were stabilized by adding four piles to each pier (Figure 1b) and a riprap around the foundations of Pier 32. No structural reinforcement was applied to Pier 30, as it is situated close to the bank, where the bed level is higher and apparently more stable. However, hydraulic modeling of the river reach indicates that, for high water depth conditions, the flow tends to concentrate on the right bank so that it cannot be excluded that also Pier 30 could be significantly stressed during a future flood event.

A real-time risk assessment system for Pier 30 was, therefore, designed and installed as a nonstructural alternative to more expensive consolidations works, as described in Section 4.

\section{1 | Geometry and structural model}

Pier 30 (Figure 2) is composed of two parallel frames at $9.50 \mathrm{~m}$ with three concrete circular piles constituting both the foundation and the support of the deck. The center-to-center distance between the first and last pile in the flow direction is $8.50 \mathrm{~m}$. Piles have a diameter of $1.5 \mathrm{~m}$ and are reinforced by 12 rebars \#24 $\mathrm{mm}$.

Two stiff beams link transversally (in river direction) the two frames: The top one $(1.50 \times 1.50 \mathrm{~m})$ supports the saddle at $26 \mathrm{~m}$ a.s.l.; the axis of the lower one $(1.0 \times 1.5 \mathrm{~m})$ is at $18.50 \mathrm{~m}$ a.s.l.

In the longitudinal direction of the bridge, the two groups of three piles are linked only by the saddle (length $27.35 \mathrm{~m}$, height $3.32 \mathrm{~m}$ ) that simply supports four longitudinal beams, characterized by a height of $2.35 \mathrm{~m}$ and different span $(36.15$ and $27.15 \mathrm{~m}$ ). The deck is $0.18 \mathrm{~m}$ thick. The upper surface of the pavement is at elevation $29.5 \mathrm{~m}$ a.s.l. Piles are embedded for about $40 \mathrm{~m}$ in the ground; borings indicated a mixture of sand and silt, with friction angles between $29^{\circ}$ and $34^{\circ}$.

\subsection{Actions and environmental loads}

\subsection{1 | Permanent loads}

An accurate geometrical survey was performed in year 2000 before the stabilization of the central piers. Therefore, it was possible to estimate permanent loads with a great precision for what geometrical data concern. Assuming a specific weight of $25 \mathrm{kN} / \mathrm{m}^{3}$ for reinforced concrete and specific weight of $23 \mathrm{kN} / \mathrm{m}^{3}$ for the pavements of the deck, the axial
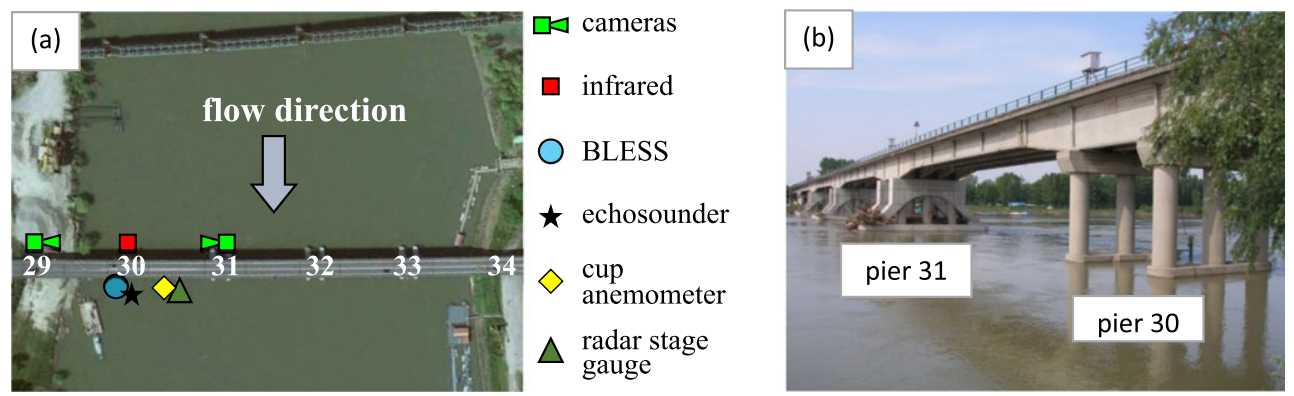

FIGURE 1 (a) Plan of Borgoforte bridge with pier numbering and locations of the sensors and (b) view of the bridge from upstream 


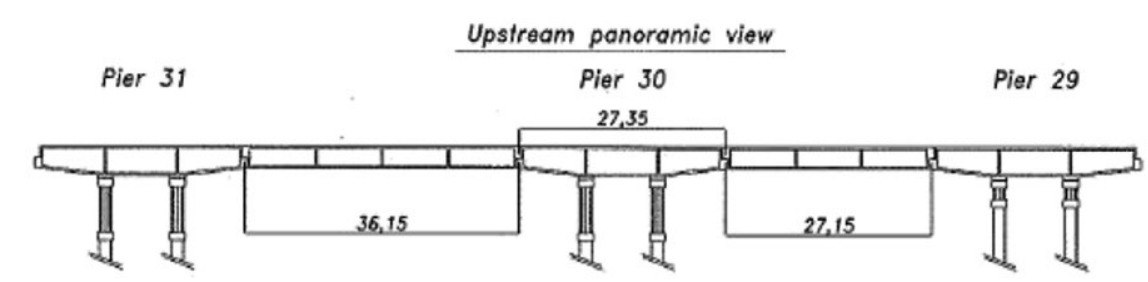

(a)

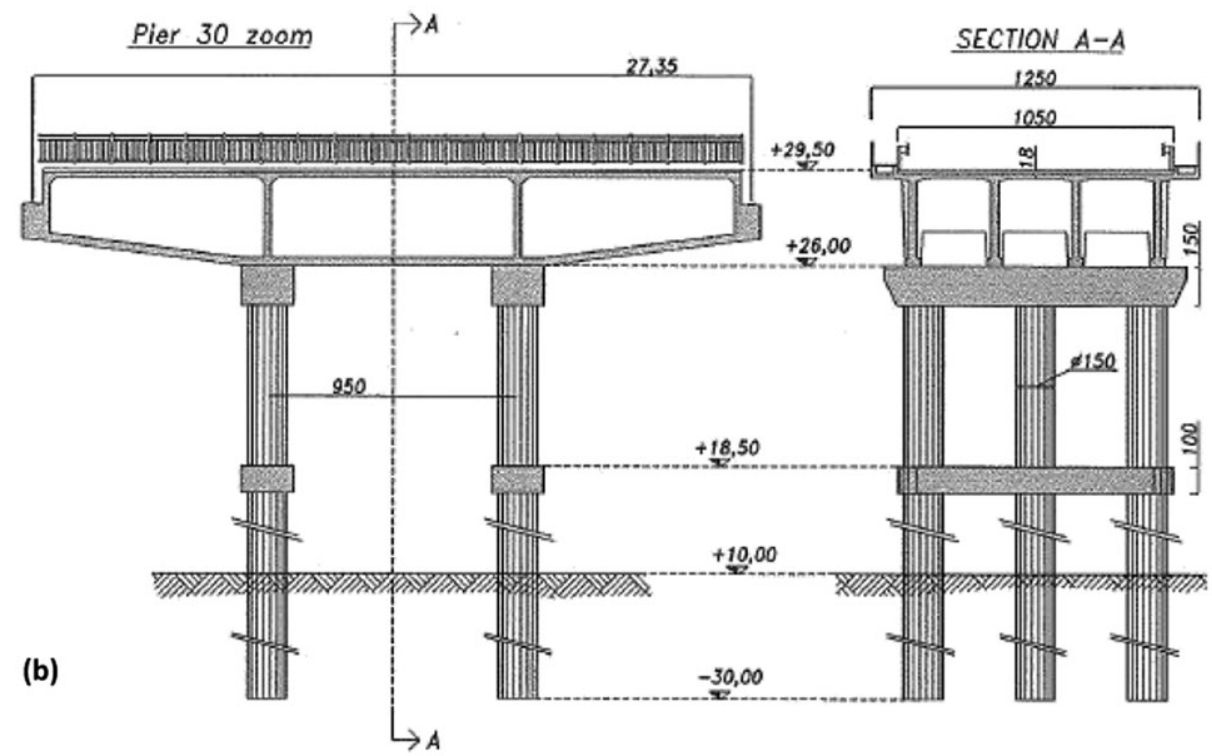

(c)

FIGURE 2 Geometry of the bridge: (a) upstream longitudinal panoramic; (b) detail of Pier 30; and (c) cross section of Pier 30

forces acting at level 17.50 in each column, due to the weight of the upper part of the pier, are 2,890 and 2,190 kN, respectively, for beam span of 36 and $27 \mathrm{~m}$, to be added to the weight of the lower part of the columns.

\subsection{2 | Water}

A variety of conditions for the river flow have been calculated by means a $2 \mathrm{D}$ river model, resulting in functional links among the river discharge, the water elevation, and the (depth-averaged) velocity at the pier. Values of water elevation and velocity are, respectively, about $22 \mathrm{~m}$ a.s. 1 . and $3.1 \mathrm{~m} / \mathrm{s}$ for a return period $T=5$ years and about $25 \mathrm{~m}$ a.s.l. and $3.8 \mathrm{~m} / \mathrm{s}$ for a return period $T=200$ years. Level $25 \mathrm{~m}$ a.s.l. can also be considered as a maximum value for the action: For higher water elevations, the bridge is closed to traffic, as the whole floodplain is submerged by water and the freeboard becomes insufficient; under such conditions, the structure would be left to its fate, if not even blasted to avoid an increase of the flooding upstream. Apart from low water depth conditions, flow can be considered perpendicular to the bridge and aligned with the pier, water flowing from west to east.

Drag force on each pile is evaluated by adapting the clauses of Eurocode 1991-1- $6^{20}$ to the specific site conditions. In particular, by accounting for (a) Reynolds number larger than $10^{6}$, (b) piles roughness, (c) interference of front piles with respect to the following ones, and (d) relatively high turbulence levels of the incoming flow, we assumed a total shape factor (drag coefficient) for the group of three piles as $k=2.2 .^{21-24}$ If the bed is higher than or equal to its reference elevation (10 m a.s.l.), velocity is assumed as uniformly distributed along the pile. For bed conditions lower than the reference ones, degradation is interpreted as the effect of local scour, and we make use of results in Tsutsui, ${ }^{25}$ who showed that the pressure distribution below the reference value can be approximated as linearly decreasing in the scour hole, reaching a zero value at a depth of one pile diameter under the reference bed level.

\subsection{3 | Debris}

Floating debris (trees) can pile up in front of the pier, thus increasing the wetted area subjected to water drag. Occurrence of such process is basically random, and more frequent during high water depth events; a debris 
accumulation in front of the pier should be, therefore, considered as one of the possible actions even if we are not able to define probability distributions for this process. It is worth noting that no clear prescriptions are given for the extra water load due to presence of debris; such an action was most probably not considered at the time of construction of the bridge.

Based on the indications in $\mathrm{NCHRP}^{26}$ and local field observation (with particular reference to the flood event of year 2000), we assume the upper limit for the accumulation to be a width of $14 \mathrm{~m}$ and a depth of $3 \mathrm{~m}$ below the water surface. Consequent load is computed by assigning a shape factor $k=1.8\left(\mathrm{NCHRP}^{27}\right)$, whereas the exposed surface is reduced by $25 \%$ to consider the porosity of the debris. Examples of minor accumulation of debris can be observed in Figure 1 (Pier 31) and in Figure 5.

\subsection{4 | Bed level variation}

Riverbed geometry is modified by morphological processes acting at a variety of space and time scales, especially during events characterized by high water depths and velocities. Bed level variation was typically not considered at the time of construction of the bridge; it slightly affects some loads (column weight and drag due to water) but strongly affects bending moments in the piles. Historical recordings at Pier 30 indicate oscillations of about $\pm 2 \mathrm{~m}$ around the reference bed elevation to be considered as normalcy. A multiplicity of reasons can be advocated for such variations. At a large scale, the considered reach of the river Po is relatively stable, so that no significant aggradation/degradation of the cross section is expected; however, the reach is characterized by migration of bed forms (dunes and/or bars), which are consistent with the observed bed level oscillations. In addition to natural morphological features, interference of the bridge on the flow can induce local scour around the piers. According to the reference literature, ${ }^{6,28,29}$ the geometry of Pier 30 could generate scour holes as deep as 3-4 m during a flood, and which are progressively filled afterwards. However, debris trapped around the pier modify its geometry, potentially leading to much larger scour effects. According to Melville and Dongol, ${ }^{30}$ a debris accumulation of the size previously discussed can induce scour values as large as $15 \mathrm{~m}$ when the water level is relatively low, and, consequently, the accumulation is relatively close to the bed of the river. Unfortunately, it is not possible to provide statistical characterizations of such processes: Although never observed at Pier 30 but coherently with historical recordings on the neighboring piers, local deepening up to $15 \mathrm{~m}$ must be considered as extreme values during high flood events.

\subsection{5 | Wind}

Drag forces on the deck and piles are evaluated following Eurocode 1991-1-4, ${ }^{31}$ assuming as characteristic value the 10-min mean velocity at the reference elevation of $10 \mathrm{~m}$ corresponding to 50 years return period. The Italian national code $^{32}$ provides a macrozonation of the territory disregarding wind direction. In our case, the value of $v=25 \mathrm{~m} / \mathrm{s}$ is recommended for the velocity in the absence of more sophisticated analysis based on a sufficient long period of measures. Peak pressure is given by $p=1 / 2 \rho v^{2} c_{e} c_{p} c_{d}$, where a value $\rho=1.25 \mathrm{~kg} / \mathrm{m}^{3}$ can be assumed for air density. The value of exposition category coefficient $c_{e}(z)=2.35$ was assumed considering a terrain category II corresponding to a low vegetation area (grass and isolated obstacles) and a reference height $z=10 \mathrm{~m}$ of the construction over the water level. The drag coefficient, $c_{p}$, for bridge deck depends on the ratio $b / d$, where $b=12.5 \mathrm{~m}$ is the depth of the deck and $d$ its height; for the latter, two possible values are considered: $d=4.0 \mathrm{~m}$ in the absence of traffic (but including the parapet) and $d=6.0 \mathrm{~m}$ in presence of traffic. Consequent values for the pressure coefficient are $c_{p}=1.57$ and $c_{p}=1.90$, respectively. According to Eurocode EN 1991-1-4, ${ }^{31}$ the drag coefficient for each circular aligned column may be assumed as 0.92 . For the dynamic coefficient, the value $c_{d}=1$ was assumed, considering that the frequency of the bridge (measured and numerically evaluated in different conditions for traffic and bed elevation) is greater than $1.5 \mathrm{~Hz}$.

The resultant basic pressure on the deck is $1,750 \mathrm{~N} / \mathrm{m}^{2}$, more than double than the value dictated by codes at the time of the construction of the bridge $\left(720 \mathrm{~N} / \mathrm{m}^{2}\right)$.

Measurements of the anemometer in the past 5 years (see Section 4) indicate that the prevalent wind direction is aligned with the river and that the highest values correspond to east-west orientation, thus opposite to the water direction: This would allow to reduce the reference wind intensity to be combined with the water drag; such beneficial effect may be considered when confirmed by longer time series. 


\subsection{6 | Traffic}

The total width of the deck is $12.50 \mathrm{~m}$, with two sidewalks, $1 \mathrm{~m}$ width, at the sides. Three different traffic loads scenarios may be supposed: the "design scenario" complying the codes, the "normal scenario" representing the present use of the bridge, and the "controlled scenario" in severe environmental conditions.

The design scenario depicted by Eurocode 1991-2 ${ }^{33}$ must be applied for the design of bridges for main roads in Europe. Characteristic values of loads imposed by cars, lorries, and special vehicles (e.g., for industrial transport) are given, corresponding to 1,000-years return period (or probability of exceedance of $5 \%$ in 50 years); frequent values are defined with a return period of 1 week. Due to the geometry of the bridge, three lanes of $3 \mathrm{~m}$ width must be considered. In the context of multiple lane traffic load combination rules, the lane $\mathrm{n} .1$ is supposed vertically loaded by a tandem system (TS) of two concentrated loads of $300 \mathrm{kN}$, together with uniformly distributed load (UDL) system of $9 \mathrm{kN} / \mathrm{m}^{2}$. Loads of TS on lanes n. 2 and 3 are 200 and $100 \mathrm{kN}$, respectively, whereas the UDL value is $2.5 \mathrm{kN} / \mathrm{m}^{2}$ for lanes n. 2 and 3 and for the remaining area of the deck. Frequent values for TS are evaluated as $75 \%$ of the characteristic value, $40 \%$ of the characteristic value for UDL. Horizontal forces due to breaking or acceleration are evaluated as the $60 \%$ of TS and $10 \%$ of UDL considering only one lane.

The total vertical weigh of traffic prescribed by actual codes is similar to that prescribed at the time of construction of the bridge; on the contrary, prescriptions of forces due to breaking have been doubled, thus significantly increasing the bending moments in the piles.

The normal scenario is quite different. Presence of a multitude of people along the bridge is unrealistic, only two lanes of traffic are allowed, while transit of special vehicles must be authorized in advance and may occur only without the presence of other vehicles on the bridge. Consequently, normal conditions of traffic may be described as traffic on two lanes equally loaded by a UDL system corresponding to the traffic of vehicles of mass smaller than 44 tons (roughly corresponding to a distributed load of $9 \mathrm{kN} / \mathrm{m}^{2}$ ) and without TS and loads on the remaining area. Horizontal forces due to breaking or acceleration may be evaluated as the $10 \%$ of one lane traffic vertical load.

In addition, the local authorities can decide to limit the access to the bridge when the environmental conditions are severe: In the following, such a condition will be indicated as controlled scenario, where loads are referred to the different operational condition of the bridge, from normalcy to total closure; for example, authorities may decide to prohibit transit of large trucks, rather than only to allow emergency traffic (ambulances, fire trucks, etc.).

\subsection{7 | Additional possible actions}

At least three additional actions on the bridge should be considered for inclusion in the risk scenarios, namely, (a) ship collisions, (b) ice jams, and (c) earthquakes.

The scenario of vessels of significant size navigating along of the Po River during a severe flood is unrealistic; therefore, joint probability of flood and ship collision is negligible. Ice jams are excluded due to the temperate climate of the region. Earthquakes are unpredictable events of short duration; the related risk for the structure cannot be mitigated through the proposed approach. However, it should be noted that codes do not require to consider earthquakes effects jointly with those caused by traffic, wind, and floods.

\section{3 | Collapse mechanism}

The six columns carrying a pile are at the same time the support of the deck and its foundation (Figure 3). From a static point of view, the deck may be assumed as a rigid connection of the six columns. Transversally (river flow direction), they form two parallel two-story frames; longitudinally, they form three simple frames.

In the vertical direction (Figure 3a), one must consider the permanent loads and the traffic $(\mathrm{T})$, the latter acting not symmetrically on the deck. Forces along the transversal direction are due to the wind (distributed load $q_{w}$ ) blowing on the deck and on the parts of the columns over the water level, and the water (distributed load $q_{H}$ ) on submerged parts of the columns. In the longitudinal direction (Figure $3 b$ ), one must consider the traffic breaking force $\left(T_{b}\right)$, acting on the exterior lane. The passive soil thrust, opposing to the translation and rotation of the pile, may be considered linearly growing with the depth.

In principle, three different rigid-plastic collapse mechanisms may occur depending on the length of embedment of the piles. 
FIGURE 3 Variable actions on the pier: (a) transversal and vertical components and (b) longitudinal component. Collapse mechanisms of transversal frames: (c) rigid translation; (d) rotation of the end of the piers; and (e) shear type frame

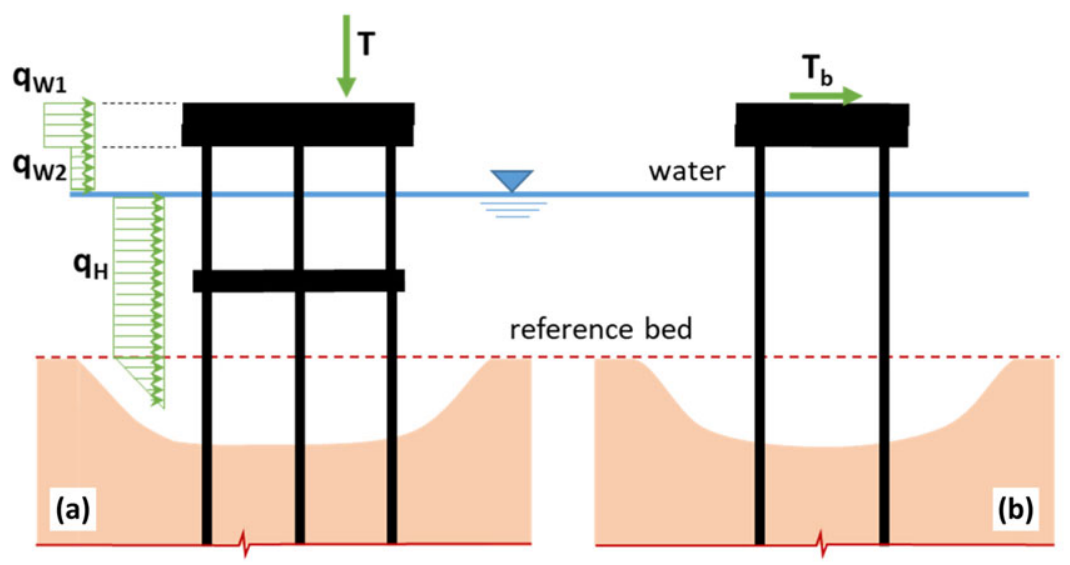

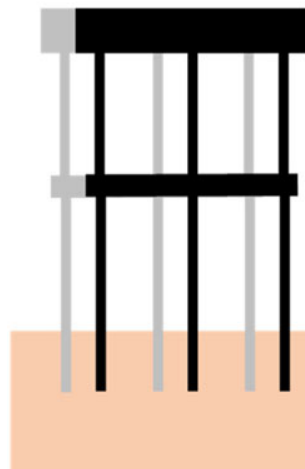

(c)

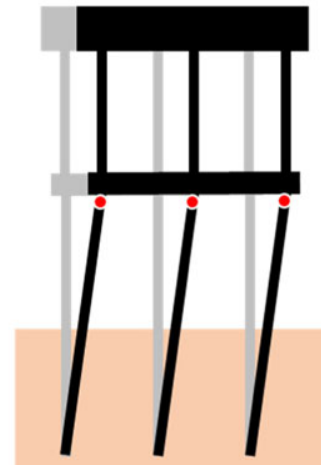

(d)

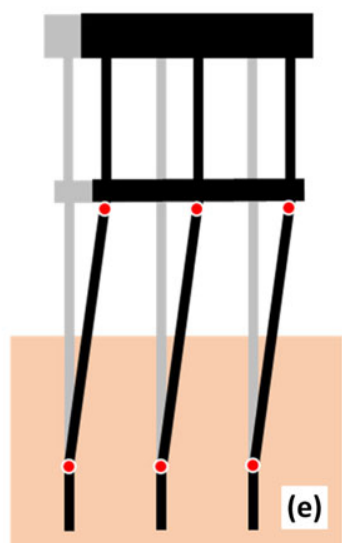

1. "Rigid translation" (Figure 3c) occurs when the length of the pier is not sufficient to activate a passive force equal to or greater than the total horizontal force acting on the pile.

2. "Rotation at the end of the piers" (Figure 3d) occurs when the embedment of the piles, sufficient in opposing to the total shear, is not sufficient to prevent the rotation at the base of the pier. The consequent collapse mechanism is formed by three plastic hinges (red circles in the figure) at the top of the columns of the first floor, whereas the bases of the piers may freely rotate, not accompanied by significant bending moments.

3. "Shear type frame" (Figure 3e) occurs when the embedment of the piers may activate a distribution of stress in the soil giving bending moments not lower than the value of the ultimate bending moment of the concrete section. The geometry of the mechanism consists of three plastic hinges as for the rotational mechanism, with the addition of three plastic hinges located in the lower embedded segment of the concrete piers.

The longitudinal one-story frame (Figure $3 b$ ) must be considered when breaking forces due to traffic act. They cause shear and bending moments that must be vectorially composed with the ones computed for the transversal frames. The position of lower plastic hinges corresponds to the section of the pier in which the moment has a maximum; that is, the shear force due to external actions and soil thrust is null. Consequently, bending moments, shears, and axial forces in the piers are easily computed imposing equilibrium conditions. Analysis of possible scenarios of actions indicates that, due to the length of the piers $(40 \mathrm{~m})$, the dominating failure mechanism is (e); case (d) only occurs in the extreme (and unrealistic) scenario of approximately $30 \mathrm{~m}$ of riverbed degradation.

\section{3 | STANDARD APPROACH TO STRUCTURAL SAFETY}

The standard approach for the diagnosis of the safety conditions of an existing construction is basically equivalent to the design of a new construction. Present codes recommend the ultimate limit states semiprobabilistic approach, where safe conditions can be synthetically expressed as $E_{d} \leq R_{d}$, where $E_{d}$ is the design value of the effect of actions such as internal 
forces, moments, or a vector representing several internal forces or moments and $R_{d}$ is the design value of the corresponding resistance.

Following Eurocode EN $1990^{13}$ (clauses 3.1 and 6.3), the design values of the effects of actions $E_{d}$ may be expressed as $E_{d}=E\left(\gamma_{F, k} \times \psi \times F_{k}, a_{d}\right)$ where

- $F_{k}$ is the characteristic value of an action, that is, its main representative value (a value with a given probability of not being exceeded on the unfavorable side during a reference period, or even a nominal value);

- $\gamma_{F, k}$ is the partial factor for the action taking into account of the possibility of unfavorable deviation of the action values from the representative values;

- $\psi=1$ if $F_{k}$ is the leading action in the combination, $\psi=\psi_{0, k}$ if $F_{k}$ is an accompanying variable action in the combination;

- $a_{d}$ is the design values of the geometrical data.

Details and coefficients for each action are as follows.

Weight of the structure, G: The collapse model involves the resistance of the most stressed pile subjected to bending moments and axial forces. The collapse of the section takes place for the yielding of rebars because the section is weakly reinforced. Thus, the permanent loads are in favor of safety, and, therefore, $\gamma_{G}=1.0$.

Wind loads, W: Following Eurocodes and the Italian code, an amplification coefficient $\gamma_{W}=1.5$ should be applied to the characteristic value. When accompanying in the combination, a coefficient $\psi_{0, W}=0.60$ is applied.

Water Loads, H: Eurocodes and the Italian code only provide generic indications for water loads. The Italian NTC states that the design must consider a flood corresponding to a return period $T \geq 200$ years. As discussed in section 2.2, a water velocity $=3.8 \mathrm{~m} / \mathrm{s}$ (corresponding to a water level $z=25 \mathrm{~m}$ a.s.l.) is the upper value for the action and may be assumed as the characteristic value; no unfavorable deviation is expected, so that $\gamma_{H}=1.0$. As accompanying action in the combination, a water velocity with return period $T=5$ years (water level at $z=22 \mathrm{~m}$ a.s.l., velocity $=3.1 \mathrm{~m} / \mathrm{s}$ ) is assumed; this corresponds to $\psi_{0, H}=(3.1 / 3.8)^{2}=0.67$ with respect to water pressure.

Traffic loads, T: Following Eurocodes and the Italian code, a coefficient $\gamma_{T}=1.35$ must be applied to the characteristic values of loads. When accompanying action in combination, tandem loads $T_{T 1}$ must be reduced by a coefficient $\psi_{0, T 1}=0.75$, distributed loads $T_{T 2}$ by a coefficient $\psi_{0, T 2}=0.40$.

Debris loads, D: No clear prescription is given for the extra water load due to presence of debris. The presence of debris is therefore left as a sensitivity parameter in the safety with the same combination coefficients used for water loads.

Bed level variation is considered a variable design geometrical data. It is therefore left as a sensitivity parameter for the diagnosis of the safety conditions.

The design resistance, $R_{d}$, is represented by the ultimate-capacity interaction diagram for combined $M_{d}$ and $N$ of the circular section of the pile, where $M_{d}$ is the design resistant bending moment and $N$ is the axial force. It was computed assuming a concrete cover of $5 \mathrm{~cm}$, concrete class $R_{b}=30 \mathrm{~N} / \mathrm{mm}^{2}$, yield stress of rebars of $430 \mathrm{~N} / \mathrm{mm}^{2}$, reduced by a coefficient 1.5 for concrete, and 1.15 for rebars in compliance by the National Code.

For each combination,

$$
\begin{aligned}
& {\left[1.0 \times G ; 1.5 \times \mathrm{W} ; 0.67 \times \mathrm{H} ; 1.35 \times\left(0.75 \times \mathrm{T}_{\mathrm{T} 1}+0.40 \times \mathrm{T}_{\mathrm{T} 2}\right)\right],} \\
& {\left[1.0 \times \mathrm{G} ; 1.5 \times 0.60 \times \mathrm{W} ; 1.0 \times \mathrm{H} ; 1.35 \times\left(0.75 \times \mathrm{T}_{\mathrm{T} 1}+0.40 \times \mathrm{T}_{\mathrm{T} 2}\right)\right],} \\
& {\left[1.0 \times \mathrm{G} ; 1.5 \times 0.60 \times \mathrm{W} ; 0.67 \times \mathrm{H} ; 1.35 \times\left(\mathrm{T}_{\mathrm{T} 1}+\mathrm{T}_{\mathrm{T} 2}\right)\right],}
\end{aligned}
$$

the structural model gives, in the lower and upper section of the $i=6$ columns, the bending moment $M_{i}$ and the corresponding axial and shear forces, $N_{i}$ and $V_{i}$, and identifies 18 points $\left(M_{i}, N_{i}\right)$ in the domain $M_{d}-N$. It is thus possible to check if all the points are internal to the resistance domain $M_{d}(N)$. In favor of safety, the collapse of the pier is identified by the formation of two plastic hinges in the most stressed pile: If one or more points are outside the resistance domain, the check must be targeted as unsafe.

In the following, we will make use of the residual moment coefficient $\left.\delta_{i}=\left[M_{d}\left(N_{i}\right)-M_{i}\right)\right] / M_{d}\left(N_{i}\right)$ to represent the distance of each point from the resistance domain in the direction of bending moments. Values of $\delta_{i}$ indicate whether point $i$ is inside $\left(\delta_{i}>0\right)$ or outside $\left(\delta_{i}<0\right)$ the resistance domain; limit conditions are expressed by $\delta_{i}=0$, that is, $M_{i}=M_{d}\left(N_{i}\right)$. Finally, the value $\delta=\min \left(\delta_{i}\right)$ will be assumed as a safety/unsafety index with respect to bridge collapse. 
The most relevant results are synthetically represented in Figure 4 where the residual moment coefficient $\delta$ is plotted against degradation of the riverbed with respect to its reference value. The curve "Eurocode with debris" represents the results obtained following the actual European and Italian codes in the presence of debris. It can be observed that the unsafe region is reached with $1.5 \mathrm{~m}$ of bed degradation; as stated above, such value can be considered as a standard fluctuation of the riverbed. The curve "Eurocode without debris" shows that, even in absence of debris, the bridge cannot stand scour depths larger than $3 \mathrm{~m}$, which is in the order of the expected scour value during a flood. The curve "ASD - traffic 1962" simulates the approach followed in the 1960s, when the bridge was designed and built. At the time, the safety checks were performed following the method of the allowable stress design (ASD), assuming a unique safety coefficient for the different actions; codes indicated lower values for wind and did not consider bed level variations. Within such scenarios, the structure could be considered as safely designed. The curve "Eurocode without traffic" indicates that the pile can resist extreme values of wind and/or water (without debris for the curve in the figure) provided that the bed level lowering does not exceed $10 \mathrm{~m}$.

In conclusion, a degradation of the riverbed larger than $2 \mathrm{~m}$, which was regularly observed in recent years, in conjunction with an extreme scenario of other actions (wind, water, and traffic) may be considered a serious hazardous condition for the bridge. This was the reason for the consolidation works on Piers 31 and 32; in principle, the same scenario applies for Pier 30 (not consolidated) although, so far, it did not experience such extreme conditions as those prescribed by codes for the design of constructions.

\section{4 | ALTERNATIVE APPROACH TO STRUCTURAL RISK: MANAGEMENT}

The novel approach here proposed for the bridge risk management is grounded on deterministic evolution scenarios of the safety conditions of the structure, thus allowing to decide about the necessity of closing the bridge to traffic in due time. This would prevent casualties and, by reducing loads connected with traffic, possibly also avoid collapse of the structure. We propose a decision support system for dynamic safety management whose main components are

(1) a monitoring system measuring in real time the physical parameters that control actions on the structure (loads and bed elevation);

(2) evolution models for such variables; predictions are provided only for the relatively short time lags required by the emergency procedures to be implemented and are conditioned by initial conditions provided by (1);

(3) structural model of the bridge using results from (2) as inputs;

(4) procedures for bridge management, that is, a system of thresholds and consequent actions;

(5) an information system (database and software) interfaced with all other components.

In the following sections, a description of components (1), (2), and (4) is given. The structural model (3) has already been described in section 2.3. The information system (5) does not require any particular comment, so that its description is omitted. Finally, some application examples for the risk management system are presented.

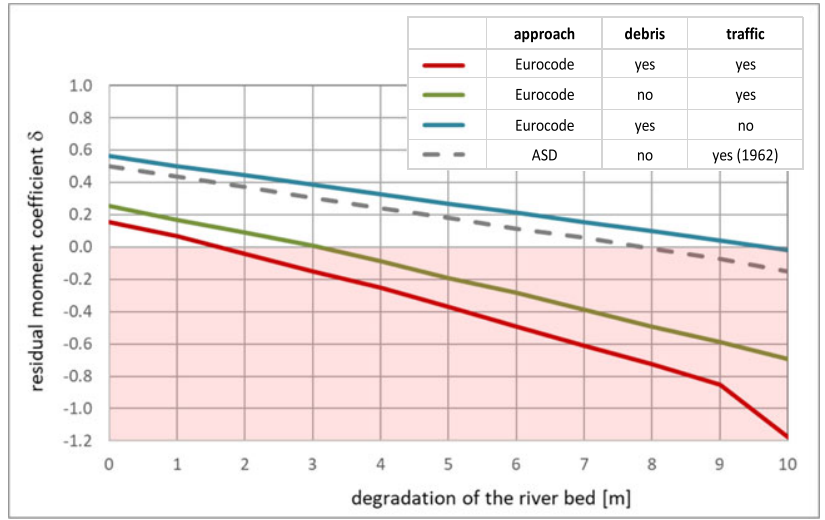

FIGURE 4 Residual moment coefficient as a function of the riverbed lowering with respect to the reference elevation. ASD: allowable stress design 


\section{1 | Monitoring system}

The main elements of the monitoring systems are the following (see Figure 1a).

- A cup anemometer is mounted over the bridge deck, measuring intensity (range: $0.38-60 \mathrm{~m} / \mathrm{s}$; resolution: $0.1 \mathrm{~m} / \mathrm{s}$ ) and direction (range: $0-360^{\circ}$; resolution: $0.4^{\circ}$ ) of the wind at a frequency of $1 \mathrm{~Hz}$.

- A radar water elevation gauge (maximum range: $35 \mathrm{~m}$; resolution: $1 \mathrm{~mm}$; frequency: $1 \mathrm{~Hz}$ ) is mounted at the side of the bridge deck, measuring water elevation approximately at the center of the river cross section. As explained in section 2.2, water discharge and velocity at Pier 30 are directly related to water elevation.

- Two cameras (3 Mpixel; lens: FJYV4.3 × 2.8SA-SA2) allow to visualize the front of Pier 30 in order to detect the presence of trapped debris. An infrared illumination system (maximum range: $155 \mathrm{~m}$; angle: $25^{\circ}$ ) allows for night vision. Images are interpreted with a binary (yes/no) logic: If significant quantity of debris is present, the accumulation is set to its maximum expected value.

- An echosounder (beam: $14^{\circ}$ conical; range: $0.8-100 \mathrm{~m}$; resolution: $0.1 \mathrm{~m}$; frequency: $1 \mathrm{~Hz}$ ) is mounted on the rear face of Pier 30 and measures the riverbed elevation. Maximum scour depths are expected in front of the pier, but in such position, the sensor would be exposed to floating debris that could damage it or mask its signal. No significant difference of elevations between front and rear of the pier are expected.

- A sedimeter based on fiber optic Bragg gratings (BLESS - bed level seeking system, ${ }^{34}$ patent of Politecnico di Milano), is paired to the echosounder for a redundant measurement of the riverbed elevation. Characteristics of this device are not yet standardized but can be described as follows: working principle: temperature and temperature variation; range: $25 \mathrm{~m}$; resolution: $0.50-1.0 \mathrm{~m}$, variable along the depth; max frequency: $2 \cdot 10^{-3} \mathrm{~Hz}$.

- A real-time device handles the signal acquisition and transmission to a remote server.

Traffic is not monitored, as this is not necessary for the management procedures: The bridge authorities can limit the typologies of vehicles allowed to cross the bridge, thus conditioning scenarios for traffic loads, when necessary.

Measures of bed elevation require some further comments. Although echosounders are standard in marine environments and widely used for riverbed surveys, literature suggests that they may present some criticalities as permanent sensors of riverbed elevation ${ }^{35,36}$; in particular, during high-velocity flow conditions, signals may be disturbed by the turbidity of the water and/or presence of air bubbles; moreover, depending on the geometry of the bridge, it may not be easy to mount them in such a way that the echoes are not disturbed by the bridge foundations; finally, their periodical inspection may be critical, especially for bridges over large rivers. We consequently installed the sedimeter that, despite its lower spatial and temporal resolution with respect to the echosounder, does not suffer from flow disturbances, thus providing a robust cross-check for the identification of the bed elevation. For a recent analysis of possible alternatives for bridge scour monitoring, see Wang et al. ${ }^{37}$

The monitoring system has been in operation since June 2011 and is now fully operative. Although its main purpose is to support bridge real-time management, historical data collected so far constitute a value per se, as they provide a useful insight of the environmental conditions at the bridge. If we exclude installation, which is strongly site dependent, the cost of the system can be estimated around $40 \mathrm{k} €$.

\subsection{Evolution of actions}

Evolution scenarios for actions (wind, water level, bed elevation, trapped debris, and traffic) can be defined through a variety of predictive models. The ideal choice for present application would be a forecast system that is very robust in terms of availability and reasonably accurate. The two conditions are often not jointly achievable, as accurate forecast typically come from relatively complex models requiring rich input data and a final validation through some expert judgment. As a consequence, the decision support system is grounded on a variety of models with different characteristics in terms of

- quantity and quality of required input information;

- degree of automatization rather than the need for human presence for handling the model;

- time scale required for the forecast, the longer being about $14 \mathrm{hr}$ for the whole emergency management chain (from normalcy to severe warning) and the shorter being 1-2 hr for critical choices during the alert/emergency phases. 
In the following, predictive models for the different actions are briefly presented; selection criteria among different options are discussed in section 4.3.

\subsection{1 | Water elevation}

Flood events along river Po in the reach of the bridge are typical of a big lowland river, with long duration waves and relatively mild time gradients. The river authority has a well-calibrated physically based model, which allows for accurate predictions of the water elevation (uncertainty of the order of $20 \mathrm{~cm}$ ) with a time lag of a couple of days. However, the authority responsible for the bridge (Province of Mantova) does not have direct access to such model.

A much rougher but independent and robust model for water elevations has been calibrated on the basis of historical data (from data acquired by the monitoring system, but also for significant flood events available on the literature for the river Po): The prediction is based on the maximum growths experienced by water elevation as a function of time intervals (from 2 to $14 \mathrm{hr}$ ) and of the initial water elevation. Results of this analysis show that a continuous grow rate equal to $0.35 \mathrm{~m} / \mathrm{hr}$ up to the levee elevation provides a safety-side scenario.

\subsection{2 | Debris}

Direct effect of debris is due to the increased water drag; such effect is maximum at the peak of the water wave, when the water surface and, consequently, the debris accumulation have highest elevation. For lower water elevations, when the accumulation is close to the bed, debris can strongly enhance scour processes: In fact, the extreme scour values registered at Pier 32 during the flood in year 2000 can be only explained by a pier whose effective size was increased by trapped debris.

The process is indeed complex; some schematization is here proposed with the aim of defining predictive scenarios.

- Origin of most floating vegetation is located in the upper part of the river basin, several kilometers upstream of Borgoforte. Its arrival can be therefore known in advance if information about the conditions of the upstream river network are available.

- Large quantities of floating debris are generated by intense rainfall events over a significant fraction of the river basin, so that we do not expect them to arrive at Borgoforte at low water elevations (say, lower than $20 \mathrm{~m}$ a.s.l.). This means that during the accumulation phase debris are far enough from the bed not to enhance scour at the pier.

- No standard model for the time evolution of debris accumulation is available in the literature; past experience indicates that the process evolves with time scales of several hours. Therefore, for short time lags (1-2 hr), we can assume that no significant change is expected with respect to the present state, whereas for longer lags (8-10 hr), we should assume that debris accumulation can reach its maximum possible extension $(14 \times 3 \mathrm{~m}$, as indicated in section 2.2).

- During the falling limb of the water wave, the accumulation that may have formed at the higher part of the piers slips down following the water surface; in some cases, this process may untighten the compactness of the accumulation, so that debris is progressively swept away; if this is not the case, a strong increase of scour rate could happen at the lower water elevations.

\subsection{3 | Bed elevation}

As discussed in section 2.2, main expected drivers for bed elevation at the bridge section are the migration of bed forms and the local scour around the pier (and subsequent refill). Moreover, as explained above, in the rising limb of a water wave, debris accumulation happens on the highest portion of the pier, so that it does not significantly affect scour at the base of the pier; maximum expected local scour is, consequently, 3-4 m, which added to effects of bed forms may lead to a minimum bed elevation at the pier around $5 \mathrm{~m}$ a.s.l. Such value appears as conservative if compared with the recordings of the monitoring system; moreover, analysis of past events indicates that a scour rate of $0.2 \mathrm{~m} / \mathrm{hr}$ can be assumed as a safety-side envelope of registered values.

As explained, extreme scour processes can be generated in the falling limb of the wave under the presence of persistent accumulations of debris around the pier. Data from the monitoring system would not allow to estimate scour 
rates in such condition that, in fact, should be avoided by removing the debris during the event; if the case, special expert evaluation is required.

\subsection{4 | Wind velocity}

The wind forecast is a key issue of the management of structural and infrastructural systems. At presents, two different algorithms can be implemented, namely, the short-term (0.5-2 hr) and medium-term (1-3 days) forecast.

The output of a wind short-term forecast system is usually restricted to few hours ahead the last wind measurement. It is crucial to issue alert that may protect people and goods in proximity of intense wind occurrences. As an example, the system realized by University of Genova (UNIGE) ${ }^{38}$ is currently applied to management of port operations ${ }^{39,40}$ and of high-speed railways. ${ }^{41}$ It is based on a mixed statistical-numerical procedure, trained by means of local wind measurements and implemented into an operational chain for the real-time prediction of the maximum expected wind velocity related to different nonexceeding probability levels (e.g., 90\%, 95\%, and 99\%) and different forecast horizons (e.g., 30, 60, and 90 min).

The medium-term forecast system (MTFS) can be carried out over a horizon of a few weeks even though its full representativeness is usually restricted to few days ahead the last wind measurements. It is crucial in order to plan and manage future activities and operations based upon a rational strategy inspired to safety assessment and risk management. For example, MTFS ${ }^{42}$ implemented by UNIGE is based on a cascade of three coupled numerical models: the global forecast system, the weather research and forecasting (WRF) model, and the wind interpolation model (WINDS - Wind Interpolation by Non-Divergent Schemes). The global forecast system is a numerical weather prediction system, developed and maintained at the National Weather Service of the National Oceanic and Atmospheric Administration in the United States, which performs every day four forecasts valid for the entire globe. It provides the initial and boundary conditions used to perform the simulations with WRF. WRF is a next-generation mesoscale numerical weather prediction, designed for operational forecasting as well as atmospheric research. It is used to forecast the wind every day with a time step of $1 \mathrm{hr}$, over three domains with increasing horizontal resolution: 20, 6.7, and $2.2 \mathrm{~km}$. The wind field forecasted by WRF at the highest resolution is further refined by the diagnostic WINDS model up to a horizontal resolution of $80 \mathrm{~m}$ considering local terrain features.

At present, no specific wind forecast model has been implemented for the bridge. Possible improvements of the system are briefly discussed below.

The wind monitoring on the site of the bridge is operative since 2012, a period long enough to implement a shortterm forecast system trained to provide wind forecasts up to a maximum of 2-3 hr ahead the last measurement; when added to the present system, this would represent an important support to decisions during any severe warning phase, at least with respect to transit of emergency vehicles. Besides, the operative chain described above may be particularized to the bridge site by realizing an ad hoc MTFS aiming to guarantee a good estimate of wind speed along the next $14 \mathrm{hr}$, necessary for the operations required by an alert (see section 4.3).

In the meanwhile, in the absence of more sophisticated methods, wind speed may be based on the maximum expected value given by meteorological forecast. In our case, the Centro Nazionale di Meteorologia e Climatologia Aeronautica of the Italian Defence Ministry provides with a good accuracy (Bonavita et $\mathrm{al}^{43}$ ) wind forecast up to 3 days with temporal resolution of $3 \mathrm{hr}$, using the meteorological model developed by Consortium for Small-scale Modelling; input data are acquired in the frame of the program World Weather Watch of World Meteorological Organization.

\subsection{5 | Traffic}

As previously discussed, traffic is controlled rather than forecasted, so that maximum loads can be tuned to the different operational condition of the bridge, from normalcy to total closure.

\section{3 | Bridge management}

The bridge management procedure is structured along the four standard phases adopted by the Italian Civil Protection, separated by three thresholds. Detailed description of the phases is given below; a synthesis is shown in Table 1.

The "normalcy phase" corresponds to no critical scenario foreseen within the reference reaction time, and no human intervention or evaluation is done. The "alert phase" is activated whenever some potential critical scenario is foreseen, or whenever any anomaly appears; in such a situation, an expert intervention is required. Operations to be completed during this phase are (a) a technician is contacted and gets access to the data from the monitoring system; 
TABLE 1 The risk-management procedure

\begin{tabular}{|c|c|c|c|}
\hline Phase & State of the system & Operations & $\begin{array}{l}\text { Time allocated } \\
\text { for operations }\end{array}$ \\
\hline Normalcy & No critical situation is foreseen & Evaluation through automatic indicators only & Indefinite \\
\hline Alert & Situation is evolving to potential criticality & Presence of an expert is required & At least $8 \mathrm{hr}$ \\
\hline Warning & Situation may become critical & $\begin{array}{l}\text { Procedures for closure of the traffic on the bridge } \\
\text { are adopted (controlled scenario for traffic) }\end{array}$ & At least $6 \mathrm{hr}$ \\
\hline
\end{tabular}

(b) evolution scenarios are updated, if possible, on the basis of more refined models; and (c) decisions on necessity of further actions are taken, that is, whether the subsequent warning phase should be activated. It has been estimated that such operations do not require more than $8 \mathrm{hr}$ (maximum reaction time for this phase). Coherently, at least $8 \mathrm{hr}$ are allocated for the alert phase; its actual duration depends on the evolution of the physical system. The "warning phase" is activated as a consequence of the updated scenarios, confirming the possibility of reaching critical conditions for the bridge in the following hours. Reaction time to be allocated to the procedures for diverting traffic and closing the bridge has been estimated to be less than $6 \mathrm{hr}$; such value is, therefore, assumed as minimum duration of the warning phase. The "severe warning phase" is activated when the structural model indicates that limit conditions have been reached under the measured values for actions and nominal traffic loads. As the bridge is closed to traffic, the structure may offer a residual safety margin, which could be used for allowing controlled crossing, for example, by emergency vehicles.

A clear identification of the thresholds separating the phases is key for the bridge management procedure. Typically, thresholds are based on the values registered by the monitoring system, to be compared with predefined limiting sets of values. Here, we adopt a different approach: Thresholds are primarily (although not solely) defined with respect to the time needed for the planned bridge management actions to be completed, on the basis of some forecasting models that use monitored values as initial conditions.

\subsection{1 | Alert}

The alert threshold divides the normalcy and alert phases. Threshold is reached whenever any of the following conditions is met:

1. the (worst case) evolution scenario for actions indicates that the structure may reach its limit conditions within $8+6=14 \mathrm{hr}$

2. authorized truckloads greater than 44 tons are expected within the following $14 \mathrm{hr}$;

3. any indication of malfunctioning from the diagnostic of the monitoring system.

Conditions 2 and 3 do not necessarily indicate a critical scenario for the bridge; rather, they indicate an anomaly with respect to standard working conditions for the structure; a human evaluation is therefore required.

Condition 1 represents the core of the bridge management logic: A worst-case scenario indicates that we could enter the severe warning phase within the planned reaction time; we are still far from the hazardous situation, but a human evaluation is needed for refining the forecast and decide further actions, if and when needed. Coherently with such logic, the forecast is based on a robust but rough safety-side set of models, namely,

- wind velocity $=25 \mathrm{~m} / \mathrm{s}$ (equal to 50-years return period value);

- riverbed degrades at a constant rate of $0.20 \mathrm{~m} / \mathrm{hr}$ (maximum awaited value); in practice, riverbed level is decreased by $0.20 \times 14=2.8 \mathrm{~m}$ with respect to the measured value;

- water level increases at a constant rate of $0.35 \mathrm{~m} / \mathrm{hr}$ (maximum expected value); in practice, water level is increased by $0.35 \times 14=4.9 \mathrm{~m}$, unless it reaches its upper limit ( $25 \mathrm{~m}$ a.s.l.; see section 2.2.);

- debris are trapped around the pier;

- traffic load consequent to the "normal" scenario. 
Return to normalcy is decided through human evaluation and depends on the conditions that caused alert to be entered; in particular, any significant debris accumulation must be disaggregated by natural causes and/or human intervention.

\subsection{2 | Warning}

The warning threshold divides the alert and warning phases. Threshold is reached if the evolution scenario for actions indicates that the structure may reach its limit conditions within $6 \mathrm{hr}$.

If the alert phase was entered because of Conditions 2 or 3 discussed above, a simple expert control is typically sufficient. However, if Condition 1 was the reason of the intervention, the expert acquires all possible additional information and analyzes the system evolution based on the most accurate and reasonable available forecast for that scenario. Possible modeling refinement with respect to those previously discussed are

- wind velocity: Maximum possible value within the next $6 \mathrm{hr}$ is set on the basis of meteorological forecast provided by the official agency;

- water level increase within the next $6 \mathrm{hr}$ is set based on the hydraulic model provided by the river agency;

- debris: No debris accumulation is applied on the pier if they are not observed along the river Po and its tributaries within a distance of at least $75 \mathrm{~km}$ upstream of the bridge (distance is set on the basis of a travel distance equivalent to $6 \mathrm{hr}$ with a velocity of $12 \mathrm{~km} / \mathrm{hr}$ ).

In the case no further information is available, forecast is anyway given by the models used during the normalcy phase (projected over $6 \mathrm{hr}$ ).

Typically, such forecast is less conservative with respect to the one automatically provided during the normalcy phase, so that emergency conditions may appear as more distant in time. Finally, if and when the (refined) evolution scenario indicates that an emergency may occur within the next $6 \mathrm{hr}$, the next threshold is overpassed, and the severe warning phase is activated.

\subsection{3 | Severe warning}

The severe warning threshold divides the warning and severe warning phases. Threshold coincide with limit condition of the structure under (a) measured actions and (b) traffic load consequent to the "controlled" scenario. Forecasts for actions evolution are relevant also in this phase, to decide whether the bridge can be still crossed by controlled traffic (typically, emergency vehicles). Within such perspective, short-term scenarios are sufficient (1-2 hr).

\section{4 | Results}

In this section, the bridge management scheme is demonstrated by means of two examples: (a) a back analysis of year 2014, which comprehends a significant high water elevation event where the alert threshold was reached and (b) a synthetic event where the warning threshold is reached. Please notice that all discussion refers to a "what if" simulation, as the management scheme is still not implemented.

\subsection{1 | Back analysis of year 2014}

Figure 5 provides the time series for the bed and water surface elevation and wind intensity (time-averaged values over $10 \mathrm{~min}$ ) along year 2014. Water elevation shows typical fluctuations between 15 and $20 \mathrm{~m}$ a.s.l during the winter season, a relatively low elevation period through all the spring and summer seasons, a significant high elevation event in November (up to $23.2 \mathrm{~m}$ a.s.l.). It should be noticed that $20 \mathrm{~m}$ a.s.l. correspond to 1-2 years return period flood, so that year 2014 should be considered as relatively exceptional with respect to water elevations. The bed around the pier shows some concentrated fluctuations (1-2 $\mathrm{m}$ of scour) at water peaks and a slow aggradation trend during the dry season. Finally, a pronounced bed erosion can be recognized during the November high water elevation period. Wind intensity is fluctuating within the range $\pm 10 \mathrm{~m} / \mathrm{s}$, where positive values indicate west-east direction (thus coherent with water load on the structure). Analysis of the images from the cameras indicates that small amount of floating 

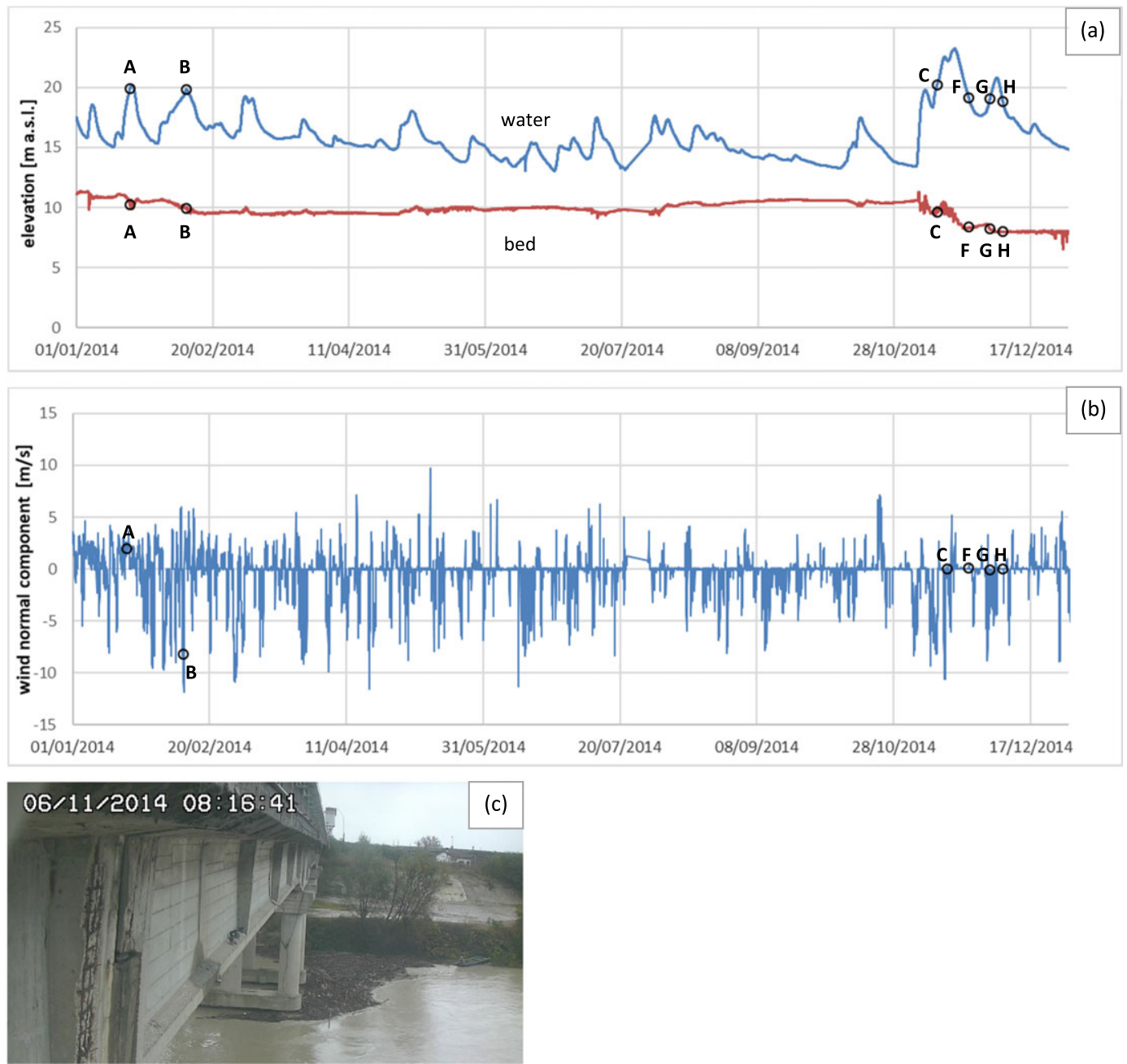

FIGURE 5 Time series of environmental actions along year 2014: (a) water and bed elevation; (b) wind velocity (averaged value over $10 \mathrm{~min}$ ); and (c) an example of debris accumulation in front of the pier

debris stopped in front of the pier during the July and November events (Figure 5c); in both cases, there was no significant imbrication, and the accumulations were swept away within a few hours.

Figure 6 shows the corresponding structural state for the bridge along the year; black line corresponds to real time values, and gray one corresponds to the worst case forecast after $14 \mathrm{hr}$ as defined for the normalcy phase. Results clearly indicate that the structure was in a comfort region during all the year: The residual moment coefficient $\delta$ is never below a robustly safe value of 0.75 . On the other side, the alert threshold was almost reached 2 times during the milder peaks


FIGURE 6 Structural state of the bridge along year 2014. (a) N-M plane (at each time only the most critical section is plotted) and (b) residual moment coefficient. Black: real time values; gray: worst-case 14-hr estimate 
of the winter period (Points A and B) and finally overpassed at a longer and more intense flood event with return time of about 20 years (Point $C$ ).

The near-alert condition (A and B) was reached with a water elevation around $20 \mathrm{~m}$ a.s.l. and bed elevation close to its reference value (10 $\mathrm{m}$ a.s.l.); these values typically correspond to short seasonal peaks that, for conditions slightly more severe of those in A and B, would have generated an alert phase of a few hours, whereas an evaluation based on more refined hydraulic model would have indicated no reason to expect the warning threshold to be reached. On the contrary, Point $\mathrm{C}$ is the start of a real alert.

According to the bridge management rules, November 12, at 6 p.m. (Point C), threshold for alert is reached, as $\delta\left(\mathrm{C}^{+14}\right) \leq 0$; a qualified operator is activated for a more refined evaluation of the evolution scenario. We can imagine that the operator gets access to the monitoring data after $2 \mathrm{hr}$ and requires three further hours to contact authorities responsible for weather and water depth forecasts (physically based models). We can finally imagine that the forecast for maximum wind velocity is $17 \mathrm{~m} / \mathrm{s}$ (instead of $25 \mathrm{~m} / \mathrm{s}$ so far assumed by the worst-case models), whereas increase for water elevation for the next $6 \mathrm{hr}$ is about $0.7 \mathrm{~m}$ (instead of $4.9 \mathrm{~m}$ as for the 14-hr worst-case forecast). At this point (November 12, time 11 p.m.) scenarios appear as in Figure 7 (Point D). Results clearly indicate the different perspectives for the normalcy phase ( $14 \mathrm{hr}$, worst-case forecast) and the alert phase ( $6 \mathrm{hr}$, refined forecast): The former indicates that limit conditions may be reached, and therefore, presence of an expert has been required for managing the alert phase; however, the less conservative scheme of the alert phase indicates that the structure will not reach any critical condition for the next $6 \mathrm{hr}$, so that there is no need (not yet, at least) for the procedures of bridge closure (warning phase).

In the following hours, the situation fluctuates across the alert threshold; let us imagine that the alert is maintained in spite of these fluctuations. Flood peak is reached on November 19, 2 a.m. (Point E), when the 6-hr forecast indicates a value for the residual moment coefficient as low as $\delta=0.47$. Finally, on November 24, 9 a.m. (Point F in Figure 7), the worst-case forecast for $\delta$ at $14 \mathrm{hr}$ becomes again larger than zero so that normalcy phase is entered again.

A further period of alert is called for the last (and lower) peak of the flood event, from December 2 to 6 (Points $G$ and $\mathrm{H}$ in Figures 5 and 6). It is interesting to notice that the alert threshold (Points $\mathrm{C}, \mathrm{F}, \mathrm{G}$, and $\mathrm{H}$ ) is reached for significantly different water elevation conditions (corresponding to very different return periods), due to relatively small variations of the riverbed level.

\subsubsection{Synthetic event (warning reached)}

A synthetic scenario for actions (Figure 8) has been generated on the basis of the flood event occurred in the year 2000 in the river Po basin, corresponding to a $\mathrm{T} \approx 200$ years return period. The event lasted about 15 days, and water elevation at the bridge reached the peak level of $25 \mathrm{~m}$ a.s.l.; bed was estimated to be scoured from +9 to $-6 \mathrm{~m}$ a.s.l. in the center of the river cross section: We will consider here that the level at Pier 30, which is close to the bank, can reach $1.3 \mathrm{~m}$ a.s.l. (from the initial value of $10 \mathrm{~m}$ a.s.l.). Significant floating debris accumulation was observed at the piers, so that we will consider their presence on Pier 30. Finally, we consider the rare case of an extreme wind event up to $23 \mathrm{~m} / \mathrm{s}$ during the peak of the flood. Such extreme conditions added to a "normal" traffic scenario would lead to the unsafe state $R_{d}<E_{d}$, so that Pier 30 may collapse.

Figure 9 shows the temporal trend for the residual moment coefficient calculated from the real-time measured actions and evaluated from forecasting models. The first relevant event is represented by Point A (Hour 103), where

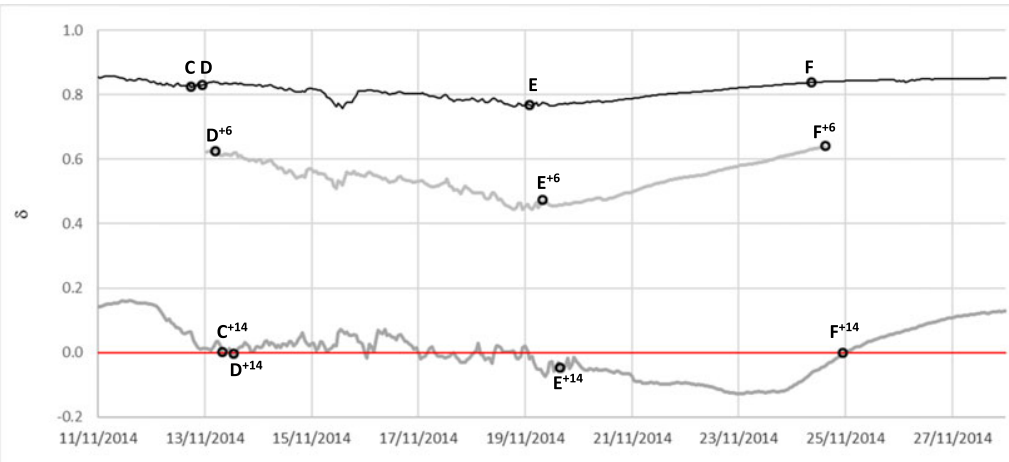

FIGURE 7 Residual moment coefficient for the different scenarios during the high stage event in winter 2014. Notice that the 6-hr forecast is defined only during the alert phase 

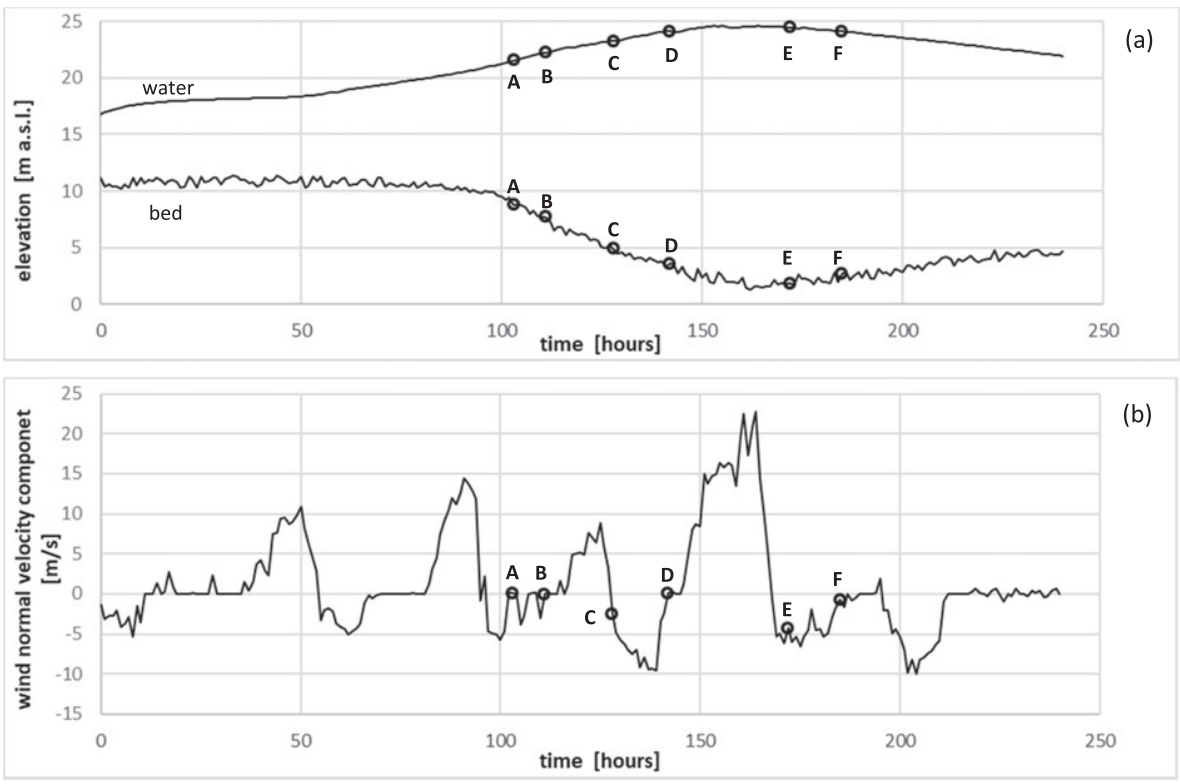

FIGURE 8 Time series of environmental actions for the synthetic event: (a) water and bed elevation and (b) wind velocity

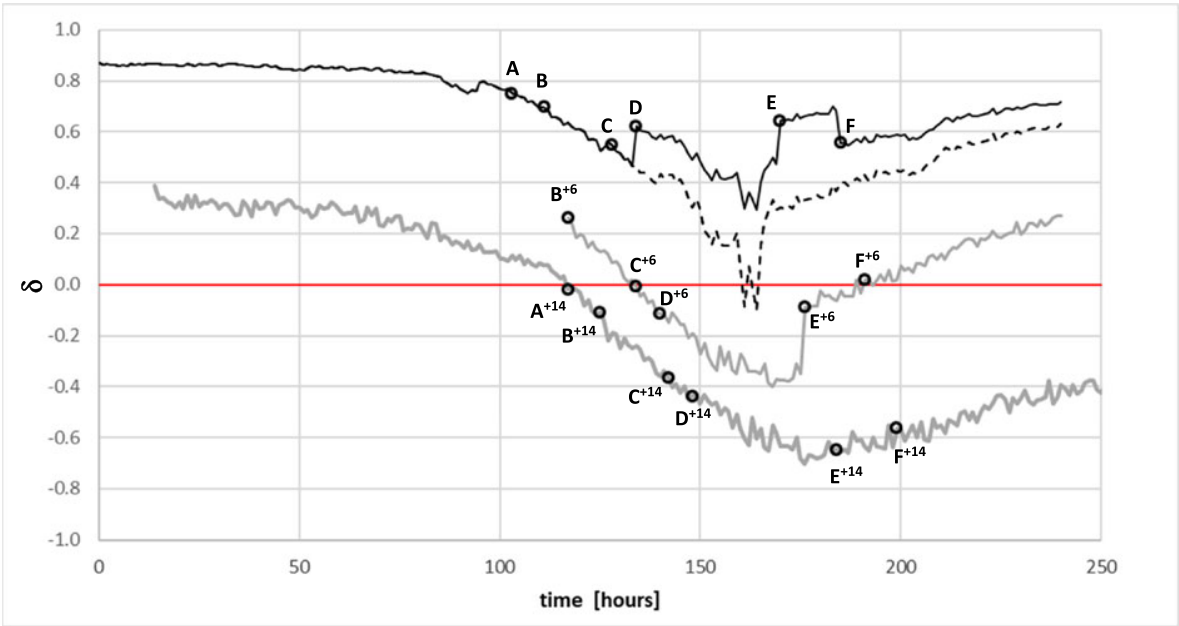

FIGURE 9 Residual moment coefficient for the different scenarios. Black: real time; gray: scenario forecasts. The dotted black line corresponds to what would happen if the bridge is not closed to traffic

the alert threshold is reached as the 14-hr forecast scenario indicates the possibility of reaching limit conditions (Point $\mathrm{A}^{+14}$ ), thus entering the alert phase with the activation of a human intervention. At least $8 \mathrm{hr}$ (Point B, Hour 111) are allocated for the definition of new evolution scenarios from refined forecasting models; due to less conservativeness of the forecasting models and the shorter time lag $(6 \mathrm{hr})$ required for the remaining management phases, situation appears as not critical until Point C (Hour 128) where the 6-hr forecast scenario (Point $\mathrm{C}^{+6}$ ) indicates the possibility of reaching limit conditions. The warning phase is therefore entered, and the procedures for traffic diversion and closure of the bridge are started. Bridge is closed to regular traffic within $6 \mathrm{hr}$ : As traffic load is set to zero, the curve $\delta(t)$ shows an abrupt increase (Point D, Hour 134). In the subsequent hours, the structure is still far from its limit conditions so that controlled transit of emergency vehicles is allowed; in particular, vehicles can access the bridge with the aim of removing debris trapped in front of the pier; such operation lasts $36 \mathrm{hr}$ until Point E (Hour 170; in Figure 9, the debris removal is plotted as an instantaneous event at Point E, whereas, in reality, it is distributed between Points D and E). Although the operation is ongoing, at Hour 164, the structure reaches its most critical state without entering the severe warning phase. Safety margins then progressively increase: Bridge can be reopened to traffic at Hour 185, when the 6-hr evolution reaches safety conditions (Point $\mathrm{F}^{+6}$ ); the subsequent progressive return to normalcy is not shown. To be noticed that, without debris removal, reopening of the traffic would have been allowed 1 day later (not shown). 


\section{5 | DISCUSSION}

\section{1 | The role of time in safety management of constructions: A conceptual framework}

The two approaches to structural safety presented in Paragraphs 3 and 4 are discussed and compared here with specific reference to the role of time, that is, the evolution of the conditions defining the safety of the structure.

Figure 10a shows a conceptual picture of the standard approach described in Paragraph 3: The health state of the structure is represented by some scalar index on the horizontal axis; the vertical axis plots some scalar index of reference actions to be considered for the safety assessment of the structure, typically representing a combination of relatively extreme and rare loading conditions. A limit curve separates the safe zone from the unsafe one, where the limiting actions decrease together with the structural health. The circle indicates present conditions in terms of heath, as periodically identified by structural monitoring, and of reference actions. Arrows indicate possible time trends: Health tends to a (slow) and progressive deterioration due to time, but it may (abruptly) increase as a consequence of rehabilitation works. Reference actions for safety assessment do not have any continuous evolution in time but can vary suddenly because of update of the building codes (typically, with an increase of actions) or due to decisions of downgrading the construction. All such movements are characterized by relatively long time scales (years) and can make the circle cross the limit curve. Following the philosophy proposed by Farrar and Worden, ${ }^{16}$ the availability of health deterioration models may allow to actively manage the life history of the construction, by forecasting reduction of health and consequently programming actions that keep the construction within the safe zone. For a discussion of bridge management strategies under a life-cycle concept, readers can, for example, refer to Frangopol et $\mathrm{al}^{44}$ and Orcesi and Frangopol. ${ }^{45}$

An equivalent plot in Figure 10b shows the conceptual picture of the alternative approach discussed in Paragraph 4. Time scales are here short (hours and days) so that the health of the structure can be considered as fixed; on the contrary, actions change continuously, as they represent the real-time values defined by the monitoring system. Starting from real-time values, actions are projected along conservative short-term evolution scenarios: If the forecast exceeds the limit curve, active management of the construction allows to prevent casualties and, if the case, to reduce actions, possibly avoiding the collapse of the structure.

In practice, a correct management plan of a construction should include both time scales: In the short term, safety should be managed along the logic of Figure 10b, whereas in the medium-long term, structural health conditions and reference actions should be updated along the logic of Figure 10a.

For the Borgoforte bridge, the standard safety assessment indicated that the structure belongs to the unsafe domain: This was not due to change in the structural health; rather, it was due to the change of reference actions (traffic and scour) with respect to the original design ones. Return to safety conditions was achieved through a standard approach (rehabilitation) for Piers 31 and 32, whereas the alternative approach of real-time management was chosen for Pier 30.
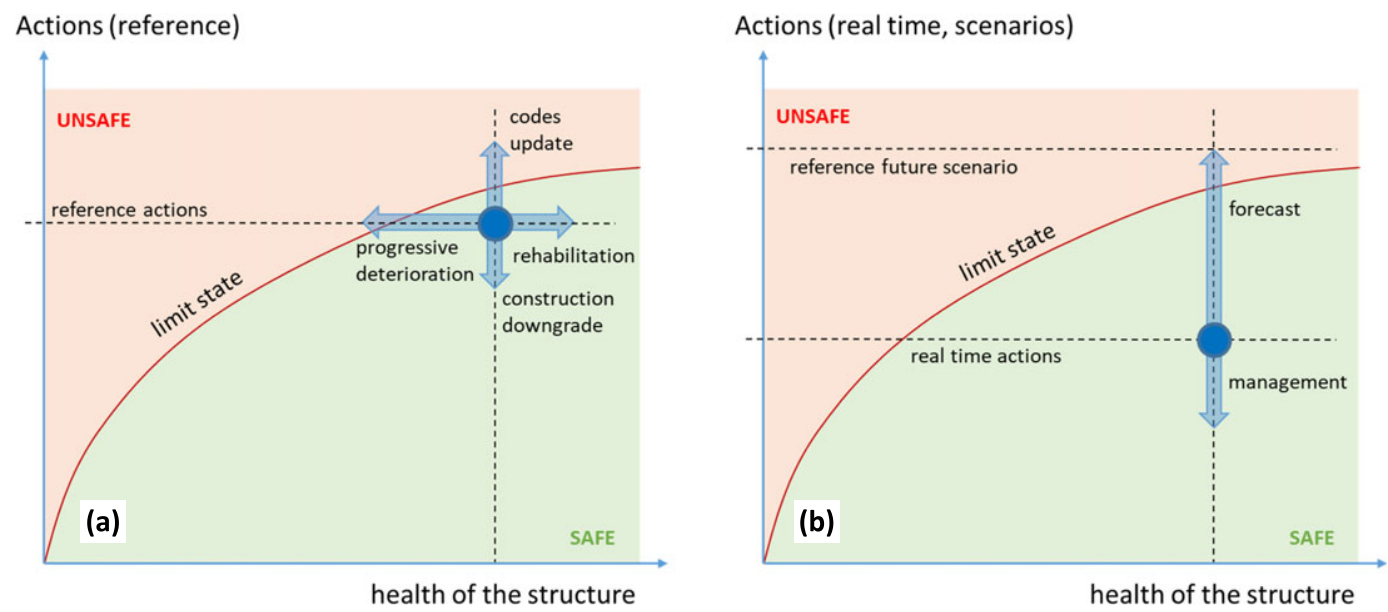

FIGURE 10 Conceptual representation of time evolution of structural safety: (a) standard approach, long time scales, and (b) present approach, short time scales 


\section{2 | Generalization of the approach to other systems}

Aiming to explore the applicability of the approach proposed here to a larger variety of systems with respect to river bridges, or to recognize and interpret similar strategies adopted in other fields, two necessary conditions can be identified, namely,

1. Procedures (temporary measures) aimed at increasing safety of the system can be performed within relatively short time interval; "short" can span from minutes to days but anyway should be much shorter than the life of the system.

2. Evolution scenarios for actions can be forecasted over time spans longer than the time intervals required for the safety measures.

These two conditions are separately discussed in the following paragraphs.

Procedures for safety management depend on the typology of the system under analysis. A major issue is the possibility of avoiding the presence of people when limit conditions are overpassed, typically by evacuation and/or by control of the access to the system. In addition to river bridges, in the introduction, we already mentioned examples such as cranes and temporary structures to be evacuated when forecasting extreme wind velocities, rather than evacuating entire areas that may be hit by tsunamis rather than by hurricanes.

In other cases, management of the operational conditions can also reduce actions and, therefore, maintain the system within its safe domain. For the Borgoforte bridge, we already discussed how this can be done by avoiding presence of large trucks, which significantly affect wind load, and by removing debris accumulations, which affect both water drag and potential of bed scour. Reduction of the velocity of high-speed trains in extreme wind conditions is another example in this sense, as an alternative to costly wind shelters. Another one is a proper management of piling containers in terminals where, under conditions of high wind velocities, empty (and, therefore, light) containers should not be left at the top of a stack.

Procedures for safety management are defined in terms of activities and related timings. The latter obviously depend on the system under consideration but also on the organizational structure of its management. For example, we have proposed time intervals of 8 and $6 \mathrm{hr}$ for the evaluation of environmental scenarios and of procedures for stopping the traffic along Borgoforte bridge. However, if necessary, such intervals could be easily reduced by a more specific organizational structure of the bridge management. From this perspective, if we consider railway bridges, it is clear that much shorter time intervals can be accepted thanks to the permanent activity of control rooms on railway systems and to the possibility of direct control of each train almost in real time.

Once time intervals required by these procedures are defined, applicability of the approach is conditioned to the possibility of forecasting the evolution of at least part of the relevant actions along such time intervals. For the case presented here, due to the characteristics of the Po River, we can benefit from reliable long-term forecasts of flow depth (and velocity): This is a typical situation for relatively large rivers in lowlands, where deterministic models of the flood wave propagation can be implemented, providing relatively accurate forecasts along several hours (or days). However, for (mountain) rivers resulting from relatively small hydrographic basins, the time interval for forecast may be reduced to a few hours, thus preventing the applicability of this approach. Potential and limits of wind forecasts have been briefly discussed in section 4.2: At present, for the Borgoforte Bridge, evolution scenarios are solely based on official weather forecasts; data from the anemometer over the bridge may be used in future for short-term forecasts (few hours) after calibrating a local stochastic wind model based on the past wind-speed time series. Also is this case, however, the time and space scales of the loading mechanism play a crucial role: mesoscale thunderstorms, for instance, occur in a so short time interval and on a so small area as to be, at least at present, unpredictable. Further environmental actions for which forecasts of evolution scenarios may be possible are rotational and translational landslides, debris flows, hurricanes, and tsunamis.

\section{3 | Costs and benefits}

An evaluation of the feasibility of the approach presented here should also consider its costs (and benefits), to be compared with those of more traditional structural measures. As explained in Section 2, for three of the four piers in the main channel of Borgoforte bridge, a standard structural consolidation was chosen, whereas for Pier 30, a nonstructural option was preferred. The reason of such choice was twofold. First, the behavior of the riverbed at the base of Pier 30 was not clear, as the little historical evidence indicated a stable riverbed level, whereas hydraulic modeling suggests 
the possibility of significant scour. Therefore, the installation of a continuous monitoring of the river behavior, with special concern on debris accumulation and riverbed elevation, appeared as a tool to better characterize the environmental actions prior to any structural choice. Second, the nonstructural approach was significantly less expensive than pier consolidation. Our experience indicates that a clear comparison of the costs of the two solutions is not straightforward, nor it can be generalized, as (a) they are strongly linked with the geometry and environmental conditions of the bridge under consideration; (b) their distribution in time is different; (c) structural rehabilitation is grounded on well-standardized practices, whereas the nonstructural approach is here proposed at a prototypal state. Once such limitations are taken into account, a few general points can be discussed as reported below.

\subsection{1 | Direct costs}

The pure cost of the monitoring hardware for Borgoforte bridge, including sensors and the acquisition device, can be estimated around $40 \mathrm{k} €$. This does not include the optical sedimeter, for which a market price still does not exist, nor include connections and installation costs, which are strongly linked to the layout of the structure. It is worth noting that, whatever the layout is, costs of the monitoring system benefits from scale effects when several piers are monitored, in contrast with structural solutions, the cost of which are basically proportional to the number of piers to be consolidated.

\subsection{2 | Control room}

Cost of maintaining a permanently active control room depends on the organizational structure of the bridge owner. In the frequent case where a control room is anyway operational, we should only consider the cost of availability of an expert whenever an alert is launched. Whatever such costs are, they would be fractioned when multiple bridges are under control within the proposed approach.

\subsection{3 | Warning}

The activation of the warning phase implies (a) direct costs due to the closure of the traffic and (b) indirect costs due to traffic disruption. Relevance of such costs depends on the frequency of the warning phase. Since the year of installation of the monitoring system, conditions for alert have been reached once (autumn/winter 2014) at the Borgoforte bridge, but without requiring warning procedures to be activated. Such result cannot, obviously, be generalized to different systems.

\subsection{4 | Bridge collapse}

As discussed, for the bridge at Borgoforte, the closure of the bridge to traffic most probably would also prevent collapse of the structure. In the more general case where the bridge management procedure can only prevent casualties, the probability of failure should be estimated in order to consider expected costs of the reconstruction.

\section{6 | CONCLUSIONS AND PERSPECTIVES}

Borgoforte bridge was evaluated not to be sufficiently safe with respect to extreme hazard scenarios (traffic, water and wind drag, and riverbed degradation); this is not the consequence of deterioration of structural health, rather is due to the evolution of codes (values and combinations of actions) and of the increased knowledge on possible hazardous environmental conditions (scour and debris) with respect to the original design.

A nonstructural risk mitigation solution has been proposed, where real-time values for environmental actions are measured and then used as inputs (initial conditions) for developing models to forecast the same actions. On the basis of these evolution scenarios, procedures are defined so that the bridge can be closed to traffic before hazardous conditions are reached, thus preventing casualties in the case of collapse of the structure. Noticeably, for the specific case under consideration, the closure of the bridge also prevents collapse, due to the reduction of loads connected with traffic and wind drag on large vehicles. 
We finally discussed the possibility of extending the proposed management scheme to other systems, at least within civil construction. From a conceptual point of view, we advocate its compliance with the basic requirements of Eurocode EN 1990:2002, basis of structural design (clause 2.1), which states that "A structure shall be designed and executed in such a way that it will (...) sustain all actions and influences likely to occur during execution and use. (...) Potential damage shall be avoided or limited by (...) eliminating or reducing the hazards to which the structure can be subjected, (...) [also] specifying control procedures for design, production, execution, and use.” It is our hope that, when and if the proposed scheme will prove its efficacy for a broader variety of cases, it may be explicitly included as a management option in codes.

\section{ACKNOWLEDGEMENTS}

The authors wish to thank two anonymous reviewers whose valuable comments allowed to significantly improve the quality of the manuscript.

\section{ORCID}

Francesco Ballio (D) http://orcid.org/0000-0002-8499-1707

Giovanni Solari (D) http://orcid.org/0000-0002-2376-4498

\section{REFERENCES}

1. Wardhana K, Hadipriono FC. Analysis of recent bridge failures in the United States. J Perform Constructed Facil. 2003;17(3):144-150.

2. Rhodes J, Trent R. Hydraulic engineering. Proc ASCE Natl Conf. 1993;1:928-933.

3. Briaud JL, Gardoni P, Yao C, Geotech J. Statistical, Risk, and Reliability Analyses of Bridge Scour. Geoenviron Eng. 2014;140(2):04013011.

4. Imhof D. Risk assessment of existing bridge structures 2004, PhD Thesis, University of Cambridge, UK.

5. Macky GH. Survey of roading expenditure due to scour 1990, report CR 90.09, DSIR Hydrology Centre, Christchurch, New Zeland

6. Melville BW, Coleman SE. Bridge scour 2000, Water Resources Publications, LLC, Highlands Ranch, Colorado, USA

7. Ballio F, Bianchi A, Franzetti S, De Falco F, Mancini M. Vulnerabilità idraulica dei ponti fluviali. XXVI Convegno Nazionale di Idraulica e Costruzioni Idrauliche, Catania, Italy. 1998;3:69-80.

8. Azhari F, Loh KJ. Laboratory validation of buried piezoelectric scour sensing rods. Struct Control Health Monit. 2017;24(9), e1969):1-14.

9. Bao T, Liu Z. Vibration-based bridge scour detection: a review. Struct Control Health Monit. 2017;24(7), e1937):1-19.

10. Zevenbergen LW, Arneson LA, Hunt JH, Miller AC. Hydraulic Design of Safe Bridges. Washington D.C.: FHA; 2012, FHWA-HIF-12-018 HDS-7.

11. Arneson LA, Zevenbergen LW, Lagasse PF, Clopper PE. Evaluating Scour at Bridges. Fifth Edition, FHWA-HIF-12-003 - HEC-18 ed. Washington D.C.: FHA; 2012.

12. Alexandre K, Garrow LA, Higgins MJ, Meyer MD. Impacts of Climate Change on Scour-Vulnerable Bridges: Assessment Based on HYRISK. J Infrastruct Syst. 2013;19(2).

13. EN 1990. Eurocode, Basis of Structural Design. Brussels: CEN; 2002.

14. Lin TK, Chang YS. Development of a real-time scour monitoring system for bridge safety evaluation. Mech Syst Signal Process. 2017;82:503-518.

15. Ju SH. Determination of scoured bridge natural frequencies with soil-structure interaction. Soil Dynam Earthquake Eng. 2013;55:247-254.

16. Farrar CR, Worden K. Structural Health Monitoring: A Machine Learning Perspective. Chichester, UK: John Wiley \& Sons; 2013, introduction.

17. Cunha A, Caetano E, Magalhães F, Moutinho C. Recent perspectives in dynamic testing and monitoring of bridges. Struct Control Health Monit. 2013;20(6):853-877.

18. Biswajit B, Bursi OS, Casciati F, et al. A European association for the control of structures joint perspective. Recent studies in civil structural control across Europe. Struct Control Health Monit. 2014;21:1414-1436.

19. Zonta D, Glisic B, Adriaenssens S. Value of information: impact of monitoring on decision-making. Struct Control Health Monit. 2014;21(7):1043-1056.

20. EN 1991-1-6, Eurocode 1, actions on structures, part 1-6: general actions-actions during construction 2005, Brussels: CEN.

21. van Hinsberg NP. The Reynolds number dependency of the steady and unsteady loading on a slightly rough circular cylinder: from subcritical up to high transcritical flow state. J Fluid Struct. 2015;55:526-539. 
22. Igarashi T, Suzuki K. Characteristics of the flow around three circular cylinders. Bull JSME. 1984;27(233):2397-2404.

23. Moradian N, David S, Ting K, Cheng S. The effects of freestream turbulence on the drag coefficient of a sphere. Exp Thermal Fluid Sci. 2009;33(3):460-471.

24. FEMA P-55, Coastal construction manual: principles and practices of planning, siting, designing, constructing, and maintaining residential buildings in coastal areas, 4th Edition, 2011.

25. Tsutsui T. VI International Colloquium on Bluff Bodies Aerodynamics and Applications (BBAA), Milano, Italy, 2008, Paper no VC06

26. NCHRP. Effects of Debris on Bridge Pier Scour. Washington DC: TRB; 2010, Rep. 653.

27. NCHRP. Debris Forces on Highway Bridges. Washington, DC.: TRB; 2000, Rep. 445.

28. Richardson EV, Davis SR. Evaluating scour at bridges. Hydraulic Engineering Circular No. 18 (HEC-18). fourth ed. Washington DC: FHA; 2001.

29. Sheppard DM, Melville BW, Demir H. Evaluation of existing equations for local scour at bridge piers. J Hydraul Eng. 2014;140(1):14-23.

30. Melville BW, Dongol DM. Bridge pier scour with debris accumulation. J Hydraul Eng. 1992;118(9):1306-1310.

31. EN 1991-1-4, Eurocode 1, actions on structures, part 1-4: wind actions 2005, Brussels: CEN.

32. NTC - Nuove norme tecniche per le costruzioni 2008, Decreto del Ministero delle Infrastrutture e dei Trasporti 14 gennaio 2008 , Circolare pubblicata nella Gazzetta Ufficiale n. 47 del 26-02-09 Supplemento Ordinario n. 27, 2010, Gruppo 24 Ore editore.

33. EN 1991-2, Eurocode 1, actions on structures part 2: traffic loads on bridges 2005, Brussels: CEN.

34. Manzoni S, Crotti G, Ballio F, Cigada A, Inzoli F, Colombo E. Bless: a fiber optic sedimeter. Flow Meas Instrum. 2011;22(5):447-455.

35. Fisher M, Chowdhury MN, Khan AA, Atamturktur S. An evaluation of scour measurement devices. Flow Meas Instrum. 2013;33:55-67.

36. Ahamed T, Shim J, Jo H, Duan G. Test of low-cost sonar sensors for bridge scour monitoring. 16th Annual World Environmental and Water Resources Congress of the Environmental-and-Water-Resources-Institute (EWRI), West Palm Beach, FL $2016,78-87$.

37. Wang C, Yu X, Liang F. A review of bridge scour: mechanism, estimation, monitoring and countermeasures. Nat Hazards. 2017;87(3):1881-1906.

38. Burlando M, Pizzo M, Repetto MP, Solari G, De Gaetano P, Tizzi M. Short-term wind forecast for the safety management of complex areas during hazardous wind events. $J$ Wind Eng Ind Aerodyn. 2014;135:170-181.

39. Solari G, Repetto MP, Burlando M, et al. The wind forecast for safety management of port areas. J Wind Eng Ind Aerodyn. 2012;104-106:266-277.

40. Repetto MP, Burlando M, Solari G, De Gaetano P, Pizzo M, Tizzi M. A web-based GIS platform for the safe management and risk assessment of complex structural and infrastructural systems exposed to wind. Adv Eng Software. 2018;117:29-45.

41. Burlando M, Freda A, Ratto CF, Solari G. A pilot study of the wind speed along the Rome-Naples HS/HC railway line. Part 1-numerical modelling and wind simulations. J Wind Eng Ind Aerodyn. 2010;98(8-9):392-403.

42. Repetto MP, Burlando M, Solari G, De Gaetano P, Pizzo M. Integrated tools for improving the resilience of seaports under extreme wind events. Sustain Cities Soc. 2017;32:277-294.

43. Bonavita M, Torrisi L, Marcucci F. Ensemble data assimilation with the CNMCA regional forecasting system. Q $J$ Roy Meteorol Soc. 2010;136(646):132-145.

44. Frangopol DM, Dong Y, Sabatino S. Bridge life-cycle performance and cost: analysis, prediction, optimisation and decision-making. Struct Infrastruct Eng. 2017;13(10):1239-1257.

45. Orcesi AD, Frangopol DM. Bridge performance monitoring based on traffic data. J Eng Mech. 2013;139(11):1508-1520.

How to cite this article: Ballio F, Ballio G, Franzetti S, Crotti G, Solari G. Actions monitoring as an alternative to structural rehabilitation: Case study of a river bridge. Struct Control Health Monit. 2018;e2250. https://doi.org/ $\underline{10.1002 / \text { stc. } 2250}$ 